\title{
Effect of Polarity on Volume Conductivity of Polymers, Determined by Corona Triode Method
}

\author{
Pranvera Dhima ${ }^{1,2}$, Floran Vila ${ }^{1}$ \\ ${ }^{1}$ Department of Physics, University of Tirana, Tirana, Albania \\ ${ }^{2}$ Laboratory of Institute of Communication Technology, University of Technology, Darmstadt, Germany \\ Email: pranvera_dhima@yahoo.com
}

How to cite this paper: Dhima, P. and Vila, F. (2018) Effect of Polarity on Volume Conductivity of Polymers, Determined by Corona Triode Method. Advances in Materials Physics and Chemistry, 8, 387-400. https://doi.org/10.4236/ampc.2018.810026

Received: September 14, 2018

Accepted: October 13, 2018

Published: October 16, 2018

Copyright (c) 2018 by authors and Scientific Research Publishing Inc. This work is licensed under the Creative Commons Attribution International License (CC BY 4.0).

http://creativecommons.org/licenses/by/4.0/

\section{(c) () Open Access}

\begin{abstract}
In this paper, the effect of polarity on the volume conductivity of Kapton and polyethylene (PE), determined using the corona triode method, when the sample current depends linearly on grid potential, was studied. For the determination of volume conductivity, in addition to the analytical method, for the first time, a graphical method is presented as well. According to the experimental results, obtained by both methods, the volume conductivity values of negative corona charged samples were higher than those of the samples charged by positive corona. Considering the different nature of positive and negative coronas, these differences in results are to be expected and are in full accordance with the theoretical considerations as well. On the other hand, the good agreement between the analytical method results and those obtained by the graphical method, indicates high accuracy of the proposed analytical formula. Meanwhile, the satisfying accordance of experimental results with those found by the classical "static" and "dynamic" methods, confirms the accuracy of the corona method, for the determination of volume conductivity of polymers.
\end{abstract}

\section{Keywords}

Positive Corona, Negative Corona, Volume Conductivity, Kapton, Polyethylene

\section{Introduction}

Kapton and PE, that are ideally suited for various applications in different industries due to their electrical, physical, and mechanical properties combination, were chosen as subject of this study [1] [2]. 
The volume conductivity is considered to be a parameter of great importance among the electrical properties of polymers. In addition to the classic "static" methods (system of electrodes) [3] [4], and the "dynamic" methods, based on electron-beam irradiation effect, in thin polymeric films [5] [6], traditionally used to determine the volume conductivity, the corona triode method [7] [8] has resulted to be very effective as well.

In this paper, the effect of the corona polarity on volume conductivity of Kapton and PE, determined by the corona triode method, when the sample current depends linearly on grid potential, is studied.

\section{Theoretical Considerations}

\section{Positive and Negative Corona Discharge}

The corona discharge is described in details in [9]. Meanwhile, the generation mechanisms of positive and negative corona discharges (Figure 1(a) and Figure 1(b)), are somewhat different [10] [11].

A common feature of both positive and negative corona is the electron avalanche produced in a gas ionization process, due to collisions between electrons and neutral molecules, when the electric field exceeds a critical value. During this process, unipolar ions of the same polarity as the corona electrode are also produced. While in the case of the positive corona, electrons move towards corona electrode and unipolar ions are propelled towards the sample surface, the opposite happens in the case of negative polarity [9] [12].

In the case of a positive corona discharge in air, under atmospheric pressure conditions, the ions accumulated on the sample surface are mostly $\mathrm{H}^{+}\left(\mathrm{H}_{2} \mathrm{O}\right)_{n}$, whereas in negative corona discharge, $\mathrm{CO}_{3}^{-}$ions are generated [9] [13].

\section{Experimental Method}

\subsection{Experimental Setup}

The corona charging of the samples was carried out using the corona triode system (Figure 2(a) and Figure 2(c)), which consists of a corona electrode, a grounded electrode and a metallic grid inserted between them for controlling the level of surface potential as well as for improving the charges uniformity on the charged surface [9] [14] [15].

The corona electrode, energized from a DC high-voltage supply (FUG $\mathrm{HCN} 14-12500$ ), at $\pm 10 \mathrm{kV}$, was positioned at $70 \mathrm{~mm}$ over the grid. Meanwhile, the grid connected at different DC potentials (Model 240 A, Keithley Instruments) of the same polarity as that of the corona electrode, was situated at $10 \mathrm{~mm}$ over the grounded electrode. The sample charging current was measured using a digital picoampere meter (Model 445, Keithley Instruments). The samples were charged for $30 \mathrm{~s}$ and immediately after the charging operation, the surface potential was measured using an electrostatic voltmeter (Model 244, equipped with a probe model 1017), without any physical contact (Figure 2(b) and Figure 2(d)). 


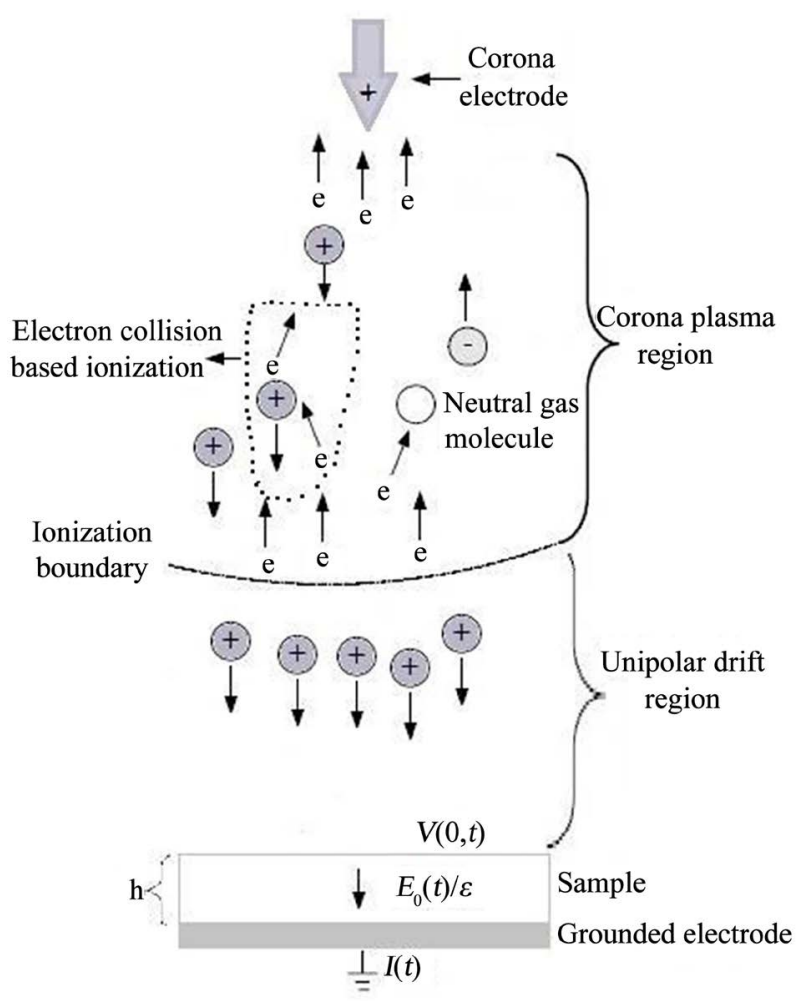

(a)

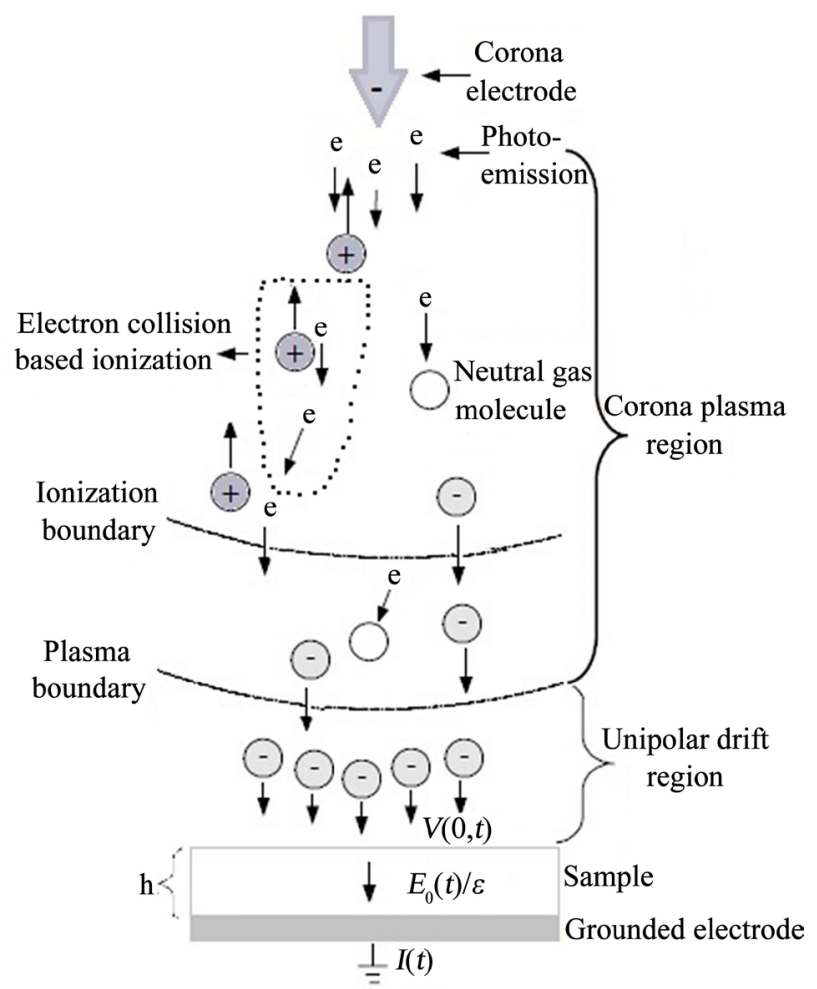

(b)

Figure 1. Scheme of (a) positive and (b) negative corona discharge. $\left(E_{0}(t), V(0, t)\right.$ and $I(t)$ are the average electric field strength, surface potential and current flowing through the sample with thickness $h$ and dielectric constant $\varepsilon$, respectively). 


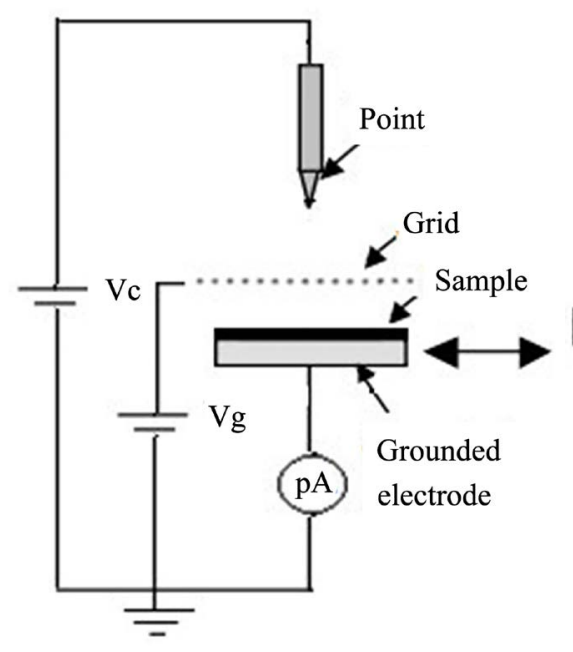

(a)

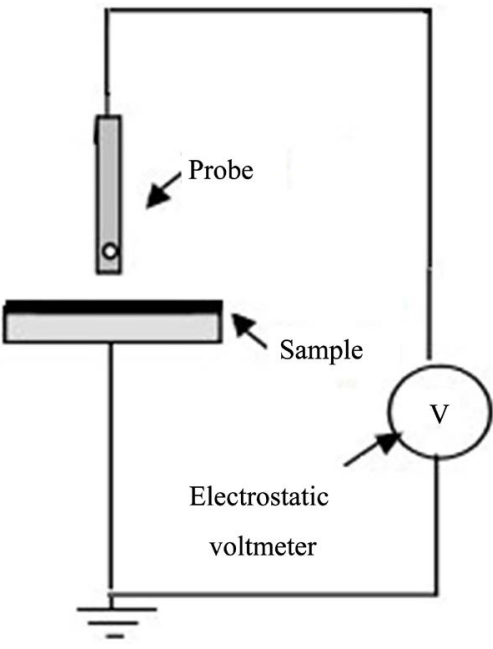

(b)

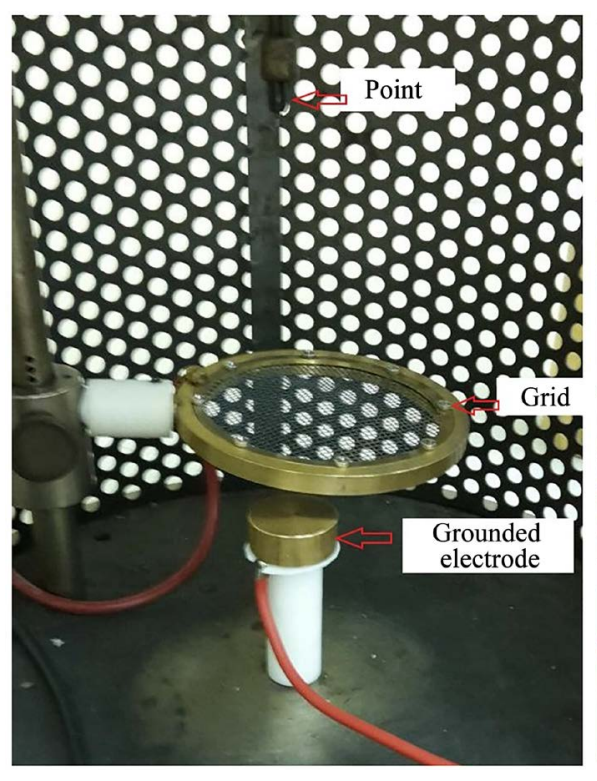

(c)

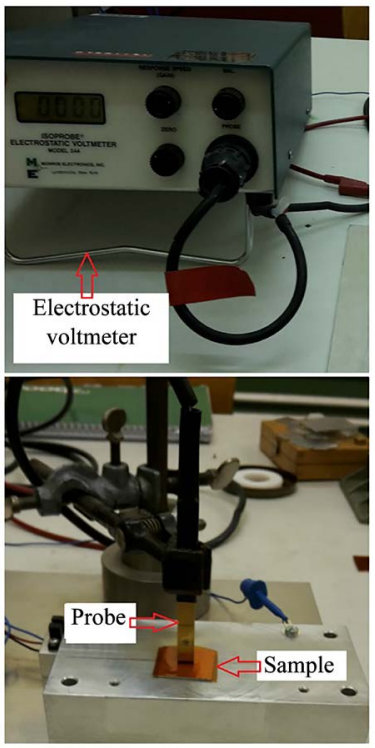

(d)

Figure 2. (a) The corona triode system scheme; (b) surface potential measurement scheme; (c) corona triode setup; (d) electrostatic voltmeter and probe [8].

\subsection{Materials Tested}

Kapton and PE samples used in experiments were cut into square sheets of 2.5 $\mathrm{cm}$ side length of $75 \mu \mathrm{m}$ and $50 \mu \mathrm{m}$ thickness, respectively. The accepted dielectric constant $(\varepsilon)$ values for Kapton and PE are 3.5 [16], and 2.25 [17] [18], respectively.

Polyimide films, commercially known as Kapton, maintain their properties over a wide range of environment temperatures of $-269^{\circ} \mathrm{C}$ to $400^{\circ} \mathrm{C}$ [19], where the other polymers would not be functional. This has made them suitable for various applications in different industries, extending their application areas with new design possibilities. It provides high resistance to chemicals and organic solvents [20], with the only disadvantage of its moderately high 
moisture absorption [19].

$\mathrm{PE}$ is the most widely used thermoplastic polymer [18] because it posseses a unique combination of properties like light weight, high chemical and abrasion resistance, low moisture permeability, that makes it ideal for a variety of applications [21].

One face of the sample was coated by an aluminum foil, to provide a good electrical contact with the grounded electrode on which were laid. For each measurement, new samples cleaned with isopropanol were used.

\subsection{Experimental Results}

The volume conductivity of Kapton and PE is determined by the corona triode method, described in details in [7]. The dependencies of the current flowing through the sample $I(t)$, and its surface potential $V(0, t)$, from the grid potential $V_{g}$, for both polarities, were experimentally revealed. The corresponding graphs, fitted with linear functions of the following types:

$$
I(t)=C V_{g}
$$

and

$$
V(0, t)=k V_{g}+V_{0},
$$

are presented in Figures 3(a), Figures 3(b) and Figures 4(a), Figures 4(b), for Kapton and PE, respectively.

The experimental constants $C, k$ and $V_{0}$ can be determined numerically from curves fitting equations.

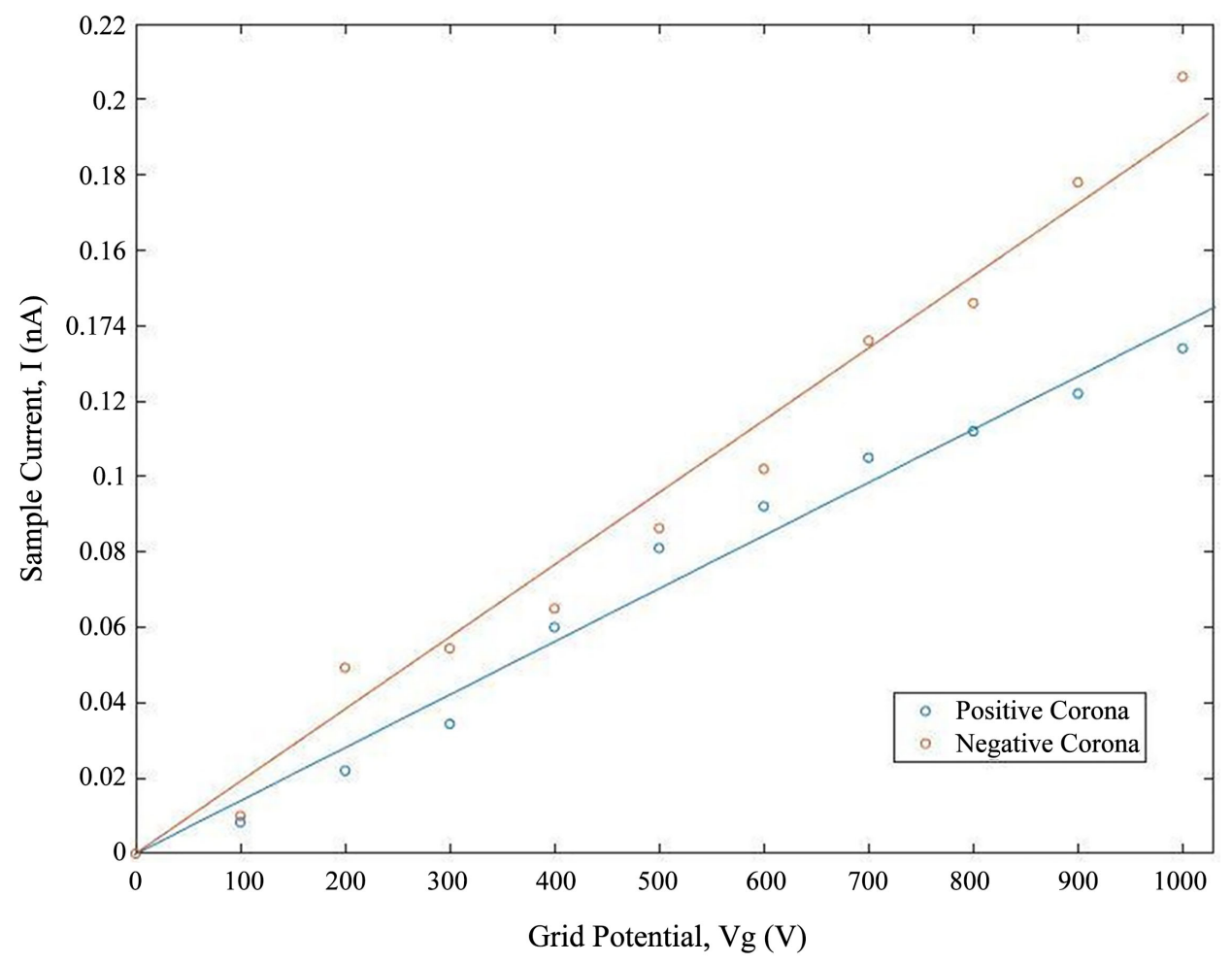

(a) 


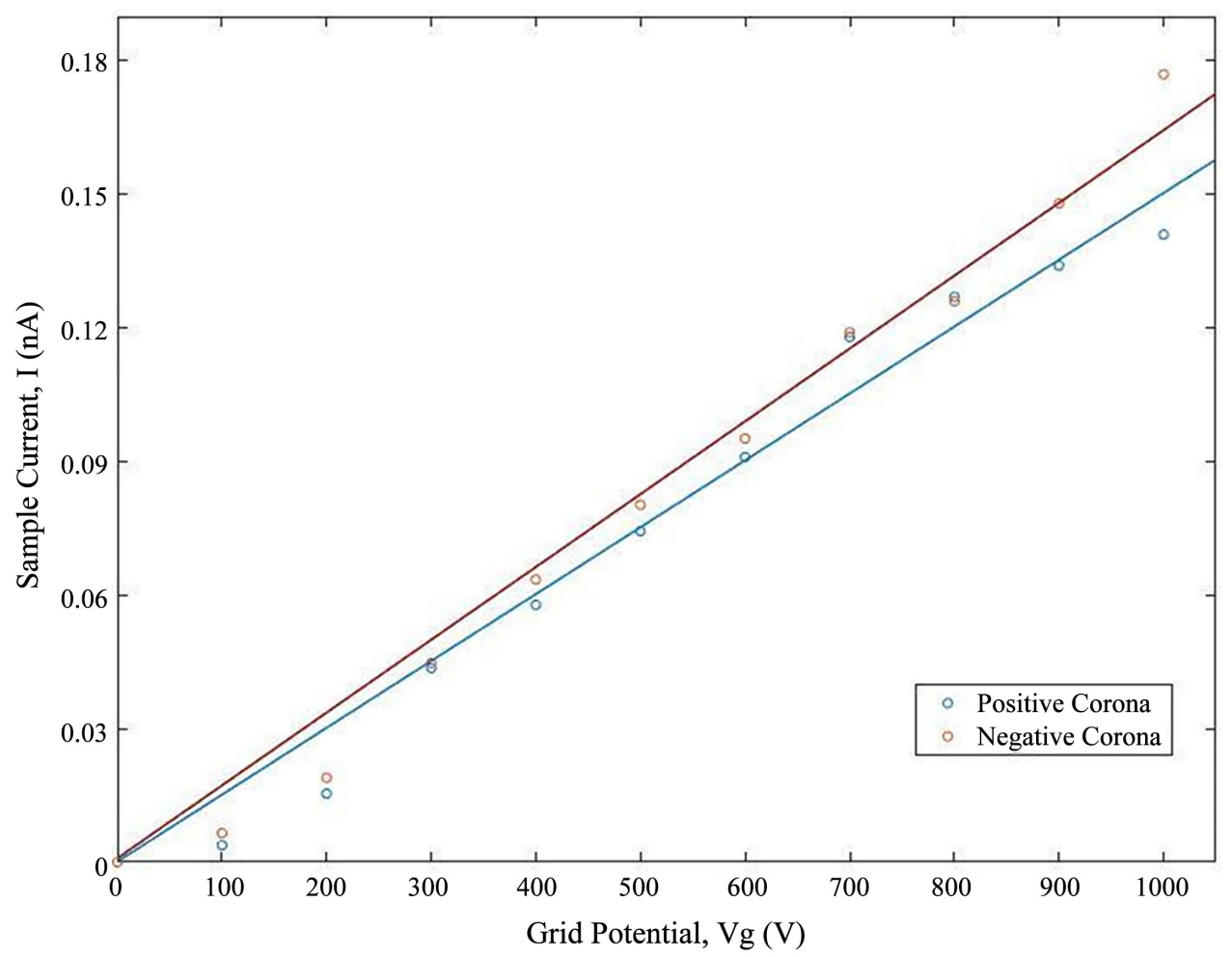

(b)

Figure 3. Dependence of the sample current on the grid potential, for both positive and negative polarity, for (a) Kapton (with $R^{2}$ values of 0.9813 and 0.9797 , respectively) and (b) PE (with $R^{2}$ values of 0.9770 and 0.9846 , respectively).

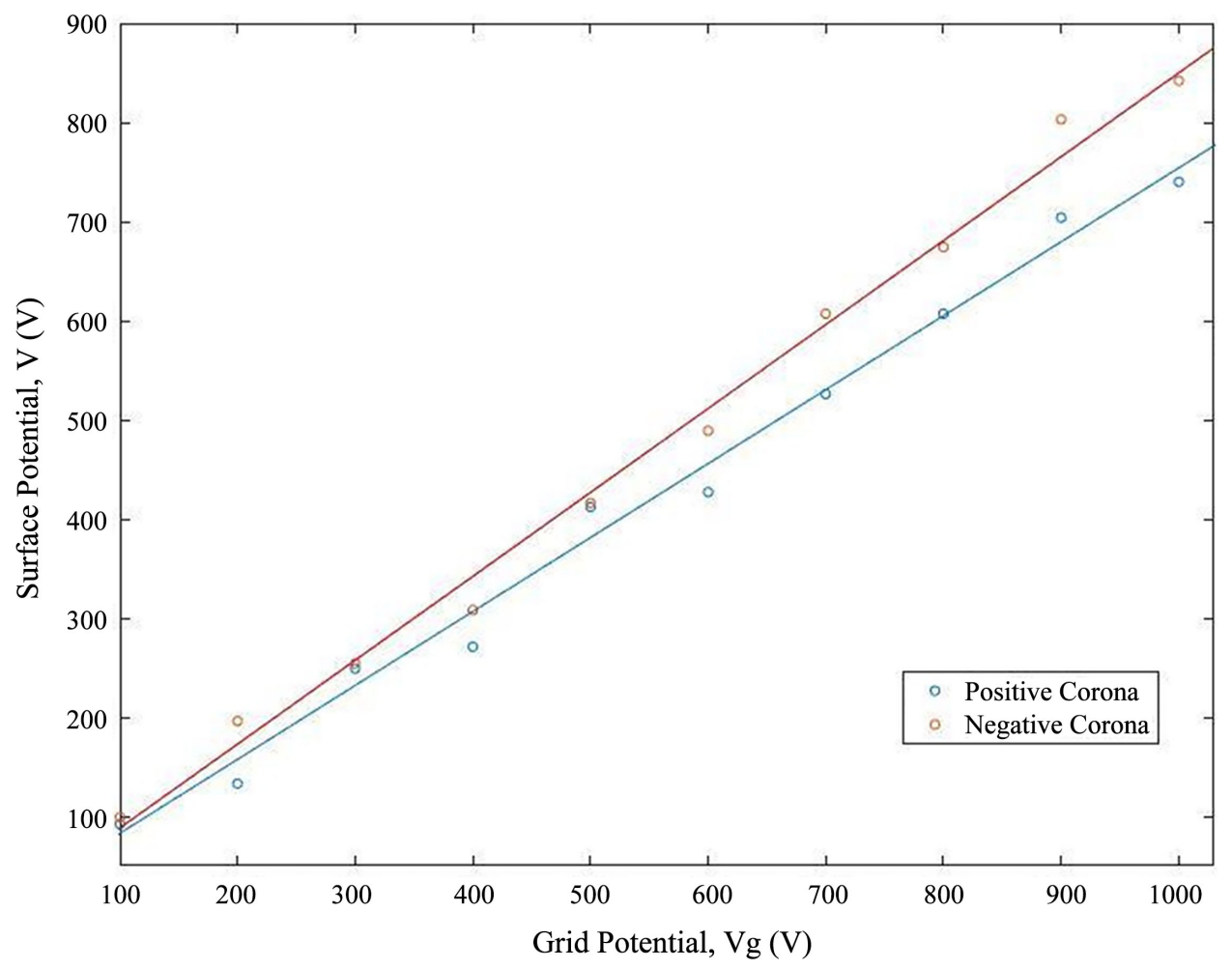

(a) 


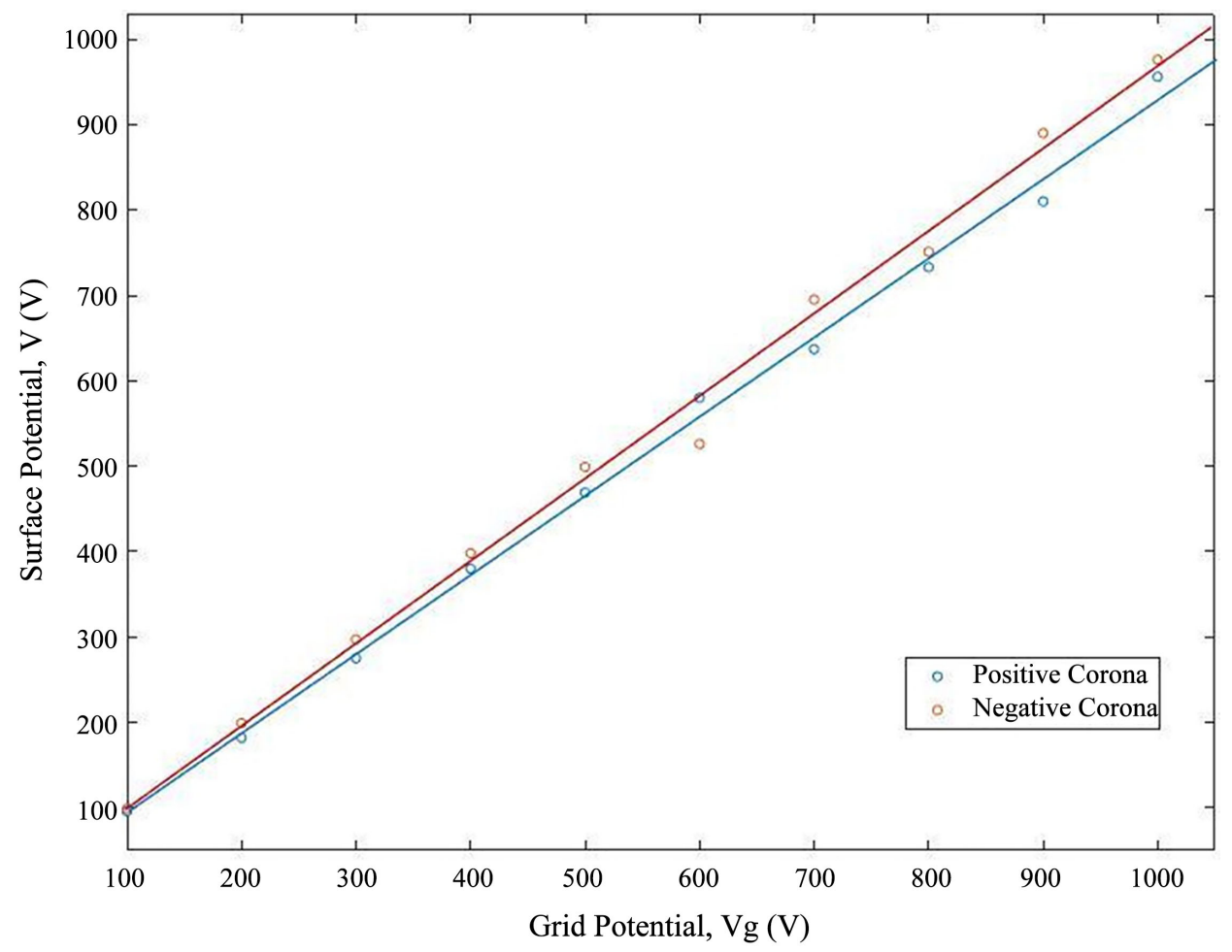

(b)

Figure 4. Dependence of the surface potential on grid potential, for both positive and negative polarity, for (a) Kapton (with $R^{2}$ values of 0.9899 and 0.9932 , respectively) and (b) PE (with $R^{2}$ values of 0.9976 and 0.9939 , respectively).

\section{Determination of Volume Conductivity}

\subsection{Graphical Determination of Volume Conductivity}

The sample was charged by the above described corona triode. According to the theory developed by [7], the relationship between the current intensity $I(t)$ at a moment of time $t$, and the surface potential $V(0, t)$, caused by that part of charges that arrives at the surface of the sample and get trapped, is:

$$
\frac{\mathrm{d}}{\mathrm{d} t} V(0, t)+\frac{\gamma}{\varepsilon_{0} \varepsilon} V(0, t)=\frac{h}{\varepsilon_{0} a^{2}} I(t),
$$

where, $\gamma$ and $a$ are volume conductivity and the length side of the square sample, respectively. Meanwhile, the other notations are the same as defined before.

In view of the fittings of the experimental results from Equation (1) and Equation (2), the differential Equation (3) can be written in the following form:

$$
\frac{\mathrm{d} V(0, t)}{\mathrm{d} t}+\left(C_{2}-C_{3}\right) V(0, t)+C_{3} V_{0}=0,
$$

where,

$$
C_{2}=\frac{\gamma}{\varepsilon_{0} \varepsilon}
$$




$$
C_{3}=\frac{h C_{1}}{\varepsilon_{0} a^{2}}
$$

and

$$
C_{1}=C / k
$$

The solution of the differential Equation (4), with the assumption that:

$$
C_{3}\left[V(0, t)-V_{0}\right]-C_{2} V(0, t)>0,
$$

which is in full accordance with the experimental facts, is given by:

$$
\frac{C_{3}\left[V(0, t)-V_{0}\right]-C_{2} V(0, t)}{C_{2} V_{0}}=\exp \left[\left(C_{3}-C_{2}\right) t\right] .
$$

In Equation (9), $C_{2}$ is the unknown quantity. Denoting:

$$
x=C_{3}-C_{2}
$$

and

$$
n=\frac{V(0, t)}{V_{0}}>1,
$$

then, Equation (9) can be written as:

$$
\frac{n x-C_{3}}{C_{3}-x}=\exp (x t) .
$$

Solving graphicaly the Equation (12) allows us to determine $x$. Meanwhile, considering Equation (5) and Equation (10), the volume conductivity $\gamma_{g}$, the object of our study, can be determined by the graphical method:

$$
\gamma_{g}=\varepsilon_{0} \varepsilon\left(C_{3}-x\right) \text {. }
$$

In view of Equation (8), Equation (10) and Equation (11), it derives that $n x-C_{3}>0$ and $C_{3}-x>0$. Thus:

$$
\frac{C_{3}}{n}<x<C_{3}
$$

The Equation (13) and the Equation (14), show that volume conductivity lies within the interval:

$$
0<\gamma_{g}<\varepsilon_{0} \varepsilon C_{3}\left(\frac{n-1}{n}\right) .
$$

Thus, the volume conductivity, can be graphically determined by formula (13) and the theoretical interval within which it is likely to be, conditioned by the extremum values of $x$, is given by Equation (15).

\subsection{Analytical Determination of Volume Conductivity}

In accordance with [7], the volume conductivity, analytically can be determined by the formula:

$$
\gamma_{a}=\frac{\varepsilon_{0} \varepsilon k_{0}(n-1)}{t\left[k_{0}+k(n+1)\right]},
$$

accepting only those experimental facts that satisfy the Equation (17) and Equa- 
tion (18):

$$
\begin{gathered}
k>\frac{k_{0}}{1+k_{0}}, \\
\frac{1}{1-k}<n<\frac{k+k_{1}}{k_{1}},
\end{gathered}
$$

where:

$$
\begin{gathered}
k_{0}=C C_{0} t, \\
C_{0}=h / \varepsilon_{0} a^{2}
\end{gathered}
$$

and

$$
k_{1}=V_{0} /\left(V_{g}\right)_{\max } .
$$

While, the theoretical interval of the volume conductivity determined by analytical method, that is conditioned by the extremum values of $n$, is given in the following form [7]:

$$
\frac{\varepsilon_{0} \varepsilon k_{0} k}{t}\left(\frac{1}{k+\alpha}\right)<\gamma_{a}<\frac{\varepsilon_{0} \varepsilon k_{0} k}{t}\left(\frac{1}{k^{2}+\beta}\right),
$$

where,

$$
\alpha=\left(k_{0}+k\right)(1-k)
$$

and

$$
\beta=k_{1}\left(k_{0}+2 k\right) .
$$

\section{Calculation Results and Analysis}

\subsection{Experimental Constants}

Table 1 and Table 2 represent the experimental constants obtained from curves fitting (Figure 3 and Figure 4) for both polarities, for Kapton and PE, respectively. The experimental constants result to be in full accordance with Equation (17) and Equation (18).

Table 1. The values of experimental constants obtained from curves fitting for Kapton, for both polarities.

\begin{tabular}{ccccccc}
\hline \multirow{2}{*}{ Corona polarity } & \multicolumn{5}{c}{ Experimental Constants } \\
\cline { 2 - 6 } & $C_{0}\left(10^{10} \Omega \cdot \mathrm{s}^{-1}\right)$ & $C\left(10^{-13} \Omega^{-1}\right)$ & $V_{0}(\mathrm{~V})$ & $k\left(10^{-1}\right)$ & $k_{0}\left(10^{-2}\right)$ & $k_{1}\left(10^{-3}\right)$ \\
\hline Positive & 1.36 & 1.41 & 2.8 & 7.5 & 5.75 & 2.8 \\
Negative & 1.36 & 1.91 & 1.9 & 8.5 & 7.79 & 1.9 \\
\hline
\end{tabular}

Table 2. The values of experimental constants obtained from curves fitting for PE, for both polarities.

\begin{tabular}{ccccccc}
\hline \multirow{2}{*}{ Corona polarity } & \multicolumn{5}{c}{ Experimental Constants } \\
\cline { 2 - 7 } & $C_{0}\left(10^{9} \Omega \cdot \mathrm{s}^{-1}\right)$ & $C\left(10^{-13} \Omega^{-1}\right)$ & $V_{0}(\mathrm{~V})$ & $k\left(10^{-1}\right)$ & $k_{0}\left(10^{-2}\right)$ & $k_{1}\left(10^{-4}\right)$ \\
\hline Positive [7] & 9.04 & 1.50 & 1.0 & 9.3 & 4.07 & 9.09 \\
Negative & 9.04 & 1.65 & 2.4 & 9.6 & 4.47 & 24.0 \\
\hline
\end{tabular}




\subsection{Graphical Solutions}

Table 3 represents the acceptable solution $x$, of Equation (12), for every grid potential value, for Kapton and PE and for both corona polarities.

\subsection{Calculation of Volume Conductivity}

\section{Graphical Calculation}

In the case of Kapton, the $99 \%$ confidence intervals, for volume resistivity determined by the graphical method, $\gamma_{(g)}$, for positive and negative polarity, are $6.12 \times 10^{-14} \mathrm{~S} \cdot \mathrm{m}^{-1}<\gamma_{+(g)}<7.88 \times 10^{-14} \mathrm{~S} \cdot \mathrm{m}^{-1}$ and $7.38 \times 10^{-14} \mathrm{~S} \cdot \mathrm{m}^{-1}<\gamma_{-(g)}<9.44 \times 10^{-14} \mathrm{~S} \cdot \mathrm{m}^{-1}$, respectively. While both polarities are involved, the $99 \%$ confidence interval for $\gamma_{(g)}$ is $7.38 \times 10^{-14} \mathrm{~S} \cdot \mathrm{m}^{-1}<\gamma_{ \pm(g)}<7.88 \times 10^{-14} \mathrm{~S} \cdot \mathrm{m}^{-1}$.

In the case of $\mathrm{PE}$, the $99 \%$ confidence interval, for volume resistivity determined by the graphical method, $\gamma_{(g)}$, is

$2.29 \times 10^{-14} \mathrm{~S} \cdot \mathrm{m}^{-1}<\gamma_{+(g)}<2.90 \times 10^{-14} \mathrm{~S} \cdot \mathrm{m}^{-1}$ for positive polarity and $2.41 \times 10^{-14} \mathrm{~S} \cdot \mathrm{m}^{-1}<\gamma_{-(g)}<3.07 \times 10^{-14} \mathrm{~S} \cdot \mathrm{m}^{-1}$ for that negative. When both polarities are involved, the $99 \%$ confidence interval for $\gamma_{(g)}$ is $2.41 \times 10^{-14} \mathrm{~S} \cdot \mathrm{m}^{-1}<\gamma_{ \pm(g)}<2.90 \times 10^{-14} \mathrm{~S} \cdot \mathrm{m}^{-1}$.

\section{Analytical Calculation}

In the case of Kapton, the $99 \%$ confidence intervals, for volume resistivity determined by the analytical method, $\gamma_{(a)}$, for positive and negative polarity, are $5.95 \times 10^{-14} \mathrm{~S} \cdot \mathrm{m}^{-1}<\gamma_{+(a)}<7.85 \times 10^{-14} \mathrm{~S} \cdot \mathrm{m}^{-1}$ and $7.21 \times 10^{-14} \mathrm{~S} \cdot \mathrm{m}^{-1}<\gamma_{-(a)}<9.42 \times 10^{-14} \mathrm{~S} \cdot \mathrm{m}^{-1}$, respectively. The $99 \%$ confidence interval for $\gamma_{(a)}$ is $7.21 \times 10^{-14} \mathrm{~S} \cdot \mathrm{m}^{-1}<\gamma_{ \pm(a)}<7.85 \times 10^{-14} \mathrm{~S} \cdot \mathrm{m}^{-1}$, when both polarities are involved.

In the case of $\mathrm{PE}$, the $99 \%$ confidence intervals, for volume resistivity determined by the analytical method, $\gamma_{(a)}$, for positive and negative polarity, are $2.52 \times 10^{-14} \mathrm{~S} \cdot \mathrm{m}^{-1}<\gamma_{+(a)}<2.90 \times 10^{-14} \mathrm{~S} \cdot \mathrm{m}^{-1}$ and $2.85 \times 10^{-14} \mathrm{~S} \cdot \mathrm{m}^{-1}<\gamma_{-(a)}<3.07 \times 10^{-14} \mathrm{~S} \cdot \mathrm{m}^{-1}$, respectively. Meanwhile, the $99 \%$ confidence interval for $\gamma_{(a)}$ is $2.85 \times 10^{-14} \mathrm{~S} \cdot \mathrm{m}^{-1}<\gamma_{ \pm(a)}<2.90 \times 10^{-14} \mathrm{~S} \cdot \mathrm{m}^{-1}$, when both polarities are involved.

In the case of Kapton, the $99 \%$ confidence interval, for volume resistivity determined involving both methods, $\gamma_{(g, a)}$, is $6.12 \times 10^{-14} \mathrm{~S} \cdot \mathrm{m}^{-1}<\gamma_{+(g, a)}<7.85 \times 10^{-14} \mathrm{~S} \cdot \mathrm{m}^{-1}$ for positive polarity, and $7.38 \times 10^{-14} \mathrm{~S} \cdot \mathrm{m}^{-1}<\gamma_{-(g, a)}<9.42 \times 10^{-14} \mathrm{~S} \cdot \mathrm{m}^{-1}$ for negative polarity. Whilst, in the case of $\mathrm{PE}$, these confidence intervals are

$2.52 \times 10^{-14} \mathrm{~S} \cdot \mathrm{m}^{-1}<\gamma_{+(g, a)}<2.90 \times 10^{-14} \mathrm{~S} \cdot \mathrm{m}^{-1}$ and

$2.85 \times 10^{-14} \mathrm{~S} \cdot \mathrm{m}^{-1}<\gamma_{-(g, a)}<3.07 \times 10^{-14} \mathrm{~S} \cdot \mathrm{m}^{-1}$, for positive and negative polarity, respectively.

Finally, the $99 \%$ confidence intervals for volume resistivity including both methods and polarities, $\gamma_{ \pm(g, a)}$, are

$7.38 \times 10^{-14} \mathrm{~S} \cdot \mathrm{m}^{-1}<\gamma_{ \pm(g, a)}<7.85 \times 10^{-14} \mathrm{~S} \cdot \mathrm{m}^{-1}$ and

$2.85 \times 10^{-14} \mathrm{~S} \cdot \mathrm{m}^{-1}<\gamma_{ \pm(g, a)}<2.90 \times 10^{-14} \mathrm{~S} \cdot \mathrm{m}^{-1}$, for Kapton and PE, respectively. 
Table 3. Graphical solution of Equation (12), for every grid potential value, for Kapton and PE.

\begin{tabular}{ccccccccc}
\hline \multicolumn{9}{c}{ Kapton } \\
\hline \multirow{2}{*}{$V_{g}(\mathrm{~V})$} & \multicolumn{2}{c}{ Positive } & \multicolumn{2}{c}{ Negative } & \multicolumn{2}{c}{ Positive } & \multicolumn{2}{c}{ Negative } \\
\cline { 2 - 9 } & $n$ & $x\left(\mathrm{~V}^{-1} \cdot \mathrm{s}^{-1}\right)$ & $n$ & $x\left(\mathrm{~V}^{-1} \cdot \mathrm{s}^{-1}\right)$ & $n$ & $x\left(\mathrm{~V}^{-1} \cdot \mathrm{s}^{-1}\right)$ & $n$ & $x\left(\mathrm{~V}^{-1} \cdot \mathrm{s}^{-1}\right)$ \\
\hline 100 & 32.86 & $1.52 \times 10^{-4}$ & 52.11 & $1.15 \times 10^{-4}$ & 96 & $3.01 \times 10^{-5}$ & 40.83 & $7.42 \times 10^{-5}$ \\
200 & 47.50 & $1.06 \times 10^{-4}$ & 103.16 & $5.88 \times 10^{-5}$ & 182 & $1.60 \times 10^{-5}$ & 82.08 & $3.73 \times 10^{-5}$ \\
300 & 88.93 & $5.70 \times 10^{-5}$ & 133.68 & $4.55 \times 10^{-5}$ & 275 & $1.06 \times 10^{-5}$ & 123.33 & $2.49 \times 10^{-5}$ \\
400 & 96.79 & $5.24 \times 10^{-5}$ & 162.11 & $3.75 \times 10^{-5}$ & 380 & $7.66 \times 10^{-6}$ & 163.33 & $1.89 \times 10^{-5}$ \\
500 & 147.14 & $3.46 \times 10^{-5}$ & 218.95 & $2.78 \times 10^{-5}$ & 469 & $6.21 \times 10^{-6}$ & 207.08 & $1.49 \times 10^{-5}$ \\
600 & 152.50 & $3.34 \times 10^{-5}$ & 257.37 & $2.37 \times 10^{-5}$ & 580 & $5.03 \times 10^{-6}$ & 218.33 & $1.41 \times 10^{-5}$ \\
700 & 187.86 & $2.71 \times 10^{-5}$ & 319.47 & $1.91 \times 10^{-5}$ & 637 & $4.58 \times 10^{-6}$ & 290.42 & $1.06 \times 10^{-5}$ \\
800 & 216.79 & $2.35 \times 10^{-5}$ & 354.74 & $1.72 \times 10^{-5}$ & 733 & $3.98 \times 10^{-6}$ & 312.50 & $9.89 \times 10^{-6}$ \\
900 & 251.43 & $2.03 \times 10^{-5}$ & 422.63 & $1.44 \times 10^{-5}$ & 810 & $3.60 \times 10^{-6}$ & 372.50 & $8.30 \times 10^{-6}$ \\
1000 & 264.29 & $1.93 \times 10^{-5}$ & 433.16 & $1.41 \times 10^{-5}$ & 956 & $3.05 \times 10^{-6}$ & 399.58 & $7.74 \times 10^{-6}$ \\
\hline
\end{tabular}

\subsection{Discussion}

The interval for volume conductivity, estimated by the graphical method, lies within the theoretical interval, given by Equation (15), for both Kapton and PE. Meanwhile, the interval for volume conductivity, determined by the analytical method, for each case, lies within the theoretical interval, given by Equation (22).

Regardless of the method used, graphical or analytical, the ratio of volume conductivity values obtained for negative polarity to those obtained for positive polarity, remains almost constant. This ratio $\frac{\bar{\gamma}_{-(g)}}{\bar{\gamma}_{+(g)}}=\frac{\bar{\gamma}_{-(a)}}{\bar{\gamma}_{+(a)}}=\frac{\bar{\gamma}_{-(g, a)}}{\bar{\gamma}_{+(g, a)}}$ is 1.20 and 1.08 in the case of Kapton and PE, respectively.

From the comparison of volume conductivity values, obtained for the same polarity, by two different methods, results a constant ratio. Thus, $\frac{\bar{\gamma}_{+(a)}}{\bar{\gamma}_{+(g)}}=\frac{\bar{\gamma}_{-(a)}}{\bar{\gamma}_{-(g)}}=\frac{\bar{\gamma}_{ \pm(a)}}{\bar{\gamma}_{ \pm(g)}}$ is 0.99 for Kapton and 1.07 for PE.

The results obtained using the graphical method, are closely similar to those obtained by the analytical method, indicating that the proposed analytical formula (16) allows the determination of volume conductivity with high accuracy.

In several studies for Kapton, volume conductivity value of $\gamma=7.69 \times 10^{-14} \mathrm{~S} \cdot \mathrm{m}^{-1}$, found by "static" methods [22], is reported. When the "dynamic" methods of irradiation with electron beam are used, the reported value is $\gamma=5.35 \times 10^{-14} \mathrm{~S} \cdot \mathrm{m}^{-1}$ [6]. In the case of PE, exposed to a positive corona and to a negative corona, the reported volume resistivity values are $\gamma=3.70 \times 10^{-14} \mathrm{~S} \cdot \mathrm{m}^{-1}$ and $\gamma=7.14 \times 10^{-14} \mathrm{~S} \cdot \mathrm{m}^{-1}$, respectively [14]. 
The above reported data are considered to be consistent with our experimental results.

\section{Effect of Corona Polarity on Volume Resistivity}

Corona polarity and ions mobility can influence the corona current and consequently the charge density on the sample surface. In negative corona, a part of free electrons on their way to the sample surface, are converted into negative ions, with a lower mobility than that of free electrons. Meanwhile, in positive corona, the positive ions, with a lower mobility than that of negative ions, do not undergo any transformation [23]. As the negative discharge contains both negative ions and electrons, unlike the positive discharge that contains only positive ions [24], charging by negative corona, results in higher charging currents and surface potentials, compared to the positive polarity [25]. Furthermore, the surface potential decays faster for the negative corona polarity [14].

The Figure 5. shows the dependence of the normalized surface potential, $V / V_{1}$ ( $V_{1}$ is the first measured value of surface potential), on time, for Kapton, for various $V_{g}$, of either positive or negative polarity.

The decay rate of surface potential depends on volume conductivity of the polymer and is directly proportional to it [26] [27]. Thus, in the case of negative corona, a greater number of charges arrive the grounded electrode through the sample and consequently the volume conductivity will be higher, compared to positive corona case.

\section{Conclusions}

In the present work, the effect of polarity on the volume conductivity of Kapton and PE, determined using the corona triode method, when the sample current depends linearly on grid potential, was studied.

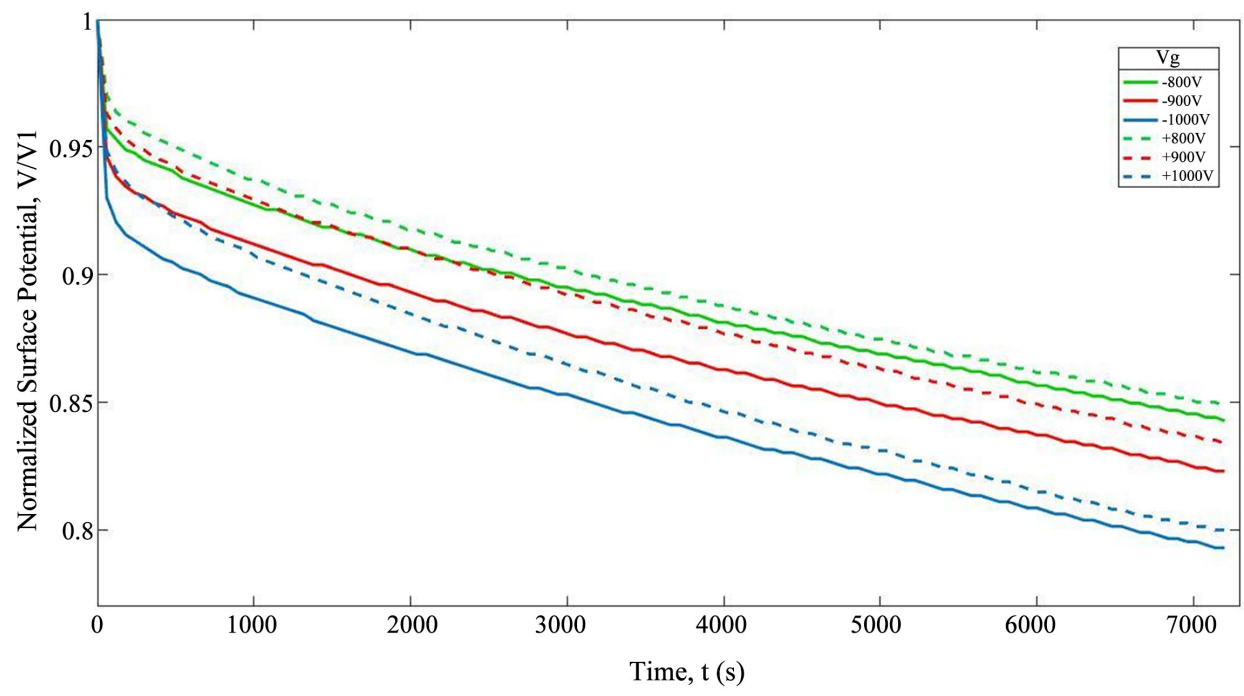

Figure 5. The normalized surface potential decay of Kapton, for various $V_{g}$ of either positive or negative polarity. (The absolute values of surface potentials are shown). 
The proposed methodology, that involves for the first time, in addition to the analytical method of determination, a graphical method as well, has a high accuracy as both methods results are closely similar.

It was found, using both methods, that volume conductivity values of negative corona charged samples were higher than those of the samples charged by positive corona, which is in full accordance with the theoretical considerations.

The experimental results are consistent with those found by the classical "static" and "dynamic" methods, which confirms the accuracy of the corona method, for the determination of volume conductivity of polymers.

\section{Conflicts of Interest}

The authors declare no conflicts of interest regarding the publication of this paper.

\section{References}

[1] Abe, K., Logan, C.M., Saneyoshi, K. and Clinard Jr., F.W. (1987) Irradiation Effects in Kapton Polyimide Film from 14-MeV Neutrons and Cobalt-60 Gamma Rays. Influence of Radiation on Material Properties. 13th International Symposium (Part II), Philadelphia, 699-681.

[2] Kong, J.S., Lee, D.J. and Kim, H.D. (2001) Surface Modification of Low-Density Polyethylene (LDPE) Film and Improvement of Adhesion between Evaporated Copper Metal Film and LDPE. Journal of Applied Polymer Science, 82, 1677-1690.

https://doi.org/10.1002/app.2008

[3] (1993) Standard Test Methods for DC Resistance or Conductance of Insulating Materials, ASTM Designation D 257-93, 103-119.

[4] Vila, F., Dhima, P. and Mandija, F. (2013) The Influence of Temperature on the Electrical Resistivity of the Cellular Polypropylene and Effect of Activation Energy. SpringerPlus, 2, 472. https://doi.org/10.1186/2193-1801-2-472

[5] Vila, F. and Sessler, G.M. (2001) Influence of Electron Beam Irradiation on Electric Parameters of Dielectric Materials. Journal of Electrostatics, 51\&52, 146-152. https://doi.org/10.1016/S0304-3886(01)00092-4

[6] Vila, F., Sessler, G.M. and Sykja, H. (2005) The Influence of Electron Beam Irradiation on the Volume Resistivity of Polyethylene and Kapton. Journal of Electrostatics, 63, 749-754. https://doi.org/10.1016/j.elstat.2005.03.039

[7] Dhima, P. and Vila, F. (2017) Determination of Volume Conductivity of Polyethylene Using Positive Corona, When the Current through the Sample Depends Linearly on Grid Potential. Journal of Materials Science and Chemical Engineering, 5 , 40-51. https://doi.org/10.4236/msce.2017.512004

[8] Dhima, P. and Vila, F. (2018) Determination of Volume Conductivity of Thin Polymeric Films Using Corona Triode, When the Current through the Sample Depends Quadratically on Grid Potential. Advances in Materials Physics and Chemistry, 8, 281-294. https://doi.org/10.4236/ampc.2018.86019

[9] Giacometti, A. and Oliveira, O.N. (1992) Corona Charging of Polymers. IEEE Transactions on Electrical Insulation, 27, 924-943. https://doi.org/10.1109/14.256470

[10] Chen, J. and Davidson, H. (2003) Model of the Negative DC Corona Plasma: Comparison to the Positive DC Corona Plasma. Plasma Chemistry and Plasma Processing, 23, 501-518. https://doi.org/10.1023/A:1023235032455 
[11] Chen, J. and Davidson, J.H. (2002) Electron Density and Energy Distributions in the Positive DC Corona: Interpretation for Corona-Enhanced Chemical Reactions. Plasma Chemistry and Plasma Processing, 22, 199-224. https://doi.org/10.1023/A:1014851908545

[12] Giacometti, A., Fedosov, S. and Costa, M. (1999) Corona Charging of Polymers: Recent Advances on Constant Current Charging. Brazilian Journal of Physics, 29, 269-279. https://doi.org/10.1590/S0103-97331999000200009

[13] Sekimoto, K. and Takayama, M. (2009) Fundamental Processes of Corona Discharge. J. Inst. Electrostat. Jpn., 33, 38-42.

[14] Moreno, R.A. and Gross, B. (1976) Measurement of Potential Buildup and Decay, Surface Charge Density and Charging Currents of Corona-Charged Polymer Foil Electrets. Journal of Applied Physics, 47, 3397. https://doi.org/10.1063/1.323199

[15] Giacometti, J.A., Ferreira, G.F. and Gross, B. (1988) A Summary of Corona Charging Methods. Proceedings of the 6th International Symposium on Electrets (ISE6), IEEE, Oxford, 1-3 September 1988, 87-91.

[16] Clark, F.M. (1962) Insulating Materials for Design and Engineering Practice. John Wiley \& Sons Inc., New York, 447.

[17] Kirby, A.J. (1992) Polyimides: Materials, Processing and Applications. Pergamon Press Ltd., Oxford, 19.

[18] Peacock, A.J. (2000) Handbook of Polyethylene: Structures, Properties and Applications. Marcel Dekker, New York, 1-28, 213.

[19] Pecht, M., et al. (1998) Electronic Packaging Materials and Their Properties. CRC Press, New York, 76.

[20] (2017) DuPont Kapton ${ }^{\circledR}$ Summary of Properties. Bulletin K-50102-5 (1/17), 1-20.

[21] Vasile, C. and Pascu, M. (2005) Practical Guide to Polyethylene. Rapra Technology Limited, 4-7.

[22] Buhler, C., Calle, C.I., Clements, J.S., Trigwell, S. and Ritz, M. (2008) New Techniques to Evaluate the Incendiary Behavior of Insulators. Proceedings ESA Annual Meeting on Electrostatics, Minneapolis, 17-19 June 2008, Paper C1, 4.

[23] Liu, D.H.F. and Liptak, B.G. (1999) Environmental Engineer's Handbook. CRC Press, New York, 131-132.

[24] Batra, I.P., Keiji, K. and Seki, H. (1970) Discharge Characteristics on Photo-Conducting Insulators. Journal of Applied Physics, 41, 3416-3422. https://doi.org/10.1063/1.1659433

[25] Iagăr, A., Diniş, C.M. and Popa, G.N. (2017) Experimental Analysis of Direct Current Corona Discharge. Materials Science and Engineering, 163, 1-9. https://doi.org/10.1088/1757-899X/163/1/012035

[26] Xing, Z., et al. (2016) Research of Surface Charge Characteristics of Epoxy Insulating Material by DC Corona. China Academic Journal Electronic Publishing House, 4, 1104-1108.

[27] Dhima, P. and Vila, F. (2017) Përcaktimi i Rezistencës Elektrike Specifike Volumore të Polietilenit, me anë të Metodës së Rënies së Potencialit të Sipërfaqes. National Conference on Natural Sciences and Technology, Natural Sciences Bulletin, Tirana, 17-18 November 2017. 